\title{
Doença falciforme, estado nutricional e sua relação com intercorrências obstétricas
}

\section{Sickle cell disease, nutritional status and its relation to obstetric complications}

\section{Isadora Garcia Pires}

Nutricionista - UNIPAM - Centro Universitário de Patos de Minas

Uberlândia - Minas Gerais

\section{Ilusk hanney Gomes de Medeiros Nóbrega Miranda}

Nutrição - UNINASSAU - Centro Universitário Maurício de Nassau

Campina Grande - PB

\section{Ingrid Rafaella Mauricio Silva Reis}

Nutricionista, UPE-Universidade de Pernambuco, Mestranda em Biociências, UNIVASF

Petrolina - PE

\section{Dr. Juscelino Kubitschek Bevenuto da Silva}

UNINASSAU-Professor do Centro Universitário Maurício de Nassau,

Campina Grande - PB

\section{RESUMO}

A anemia falciforme (AF) é uma doença autossômica recessiva, que leva à produção de hemoglobina anormal, denominada hemoglobina $S$ (HbS). Seus portadores sofrem com o crescimento deficiente, desde a infância, além de disfunções endócrinas, baixo consumo alimentar, alto requerimento energético, deficiência de minerais, que podem resultar em desnutrição. Durante a gestação, está associada ao aumento de complicações relacionadas à própria doença, morbimortalidade materna e perinatal mais elevada, nascimento de crianças com baixo peso e maiores taxas de complicações infecciosas puerperais. O objetivo do estudo foi buscar, através de uma revisão integrativa, esclarecer sobre o estado nutricional e as complicações clínicas de gestantes com anemia falciforme. Para tanto, realizou-se um estudo exploratório, por meio de pesquisa bibliográfica. Sendo a seleção e a localização das referências retiradas das bases de dados PubMed/LILACS, Plos One e da biblioteca eletrônica SciELO, utilizando também a Biblioteca Virtual em Saúde (BVS), a fim de identificar artigos científicos publicados no período entre 2008 e 2020, utilizando os seguintes descritores: anemia falciforme e intercorrências obstétricas; anemia falciforme e gestante; hemoglobina $S$ e gestante e versões em inglês. Verificou-se que gestantes portadoras de anemia falciforme possuem maior propensão a complicações, como 
aborto espontâneo, crescimento intra-uterino restrito, aumento da mortalidade fetal intra-útero, recém-nascido de baixo peso, trabalho de parto pré-termo, somados à deficiência de macro e micronutrientes durante o período gestacional, podendo chegar à desnutrição materna e à morbimortalidade materna e neonatal. Em suma, a suscetibilidade à desnutrição materna, infecções, complicações hemolíticas e vaso-oclusivas de gestantes com anemia falciforme mostrou-se um prognóstico desfavorável, trazendo consigo complicações para a mãe e o neonato. Reforçando a importância do acompanhamento nutricional como estratégia de prevenção e orientação relativas às alterações nutricionais das gestantes portadoras da doença, como alternativa para a minimização dos resultados adversos e garantir melhoria da saúde materna e fetal.

Palavras-chave: Gravidez de Alto Risco. Complicações obstétricas. Gestante.

\section{ABSTRACT}

Sickle cell anemia (SCA) is an autosomal recessive disease that leads to the production of abnormal hemoglobin called hemoglobin $\mathrm{S}(\mathrm{HbS})$. Their carriers suffer from deficient growth, since childhood, in addition to endocrine dysfunction, low food consumption, high energy requirement, mineral deficiency, which can result in malnutrition. During pregnancy, it is associated with an increase in complications related to the disease itself, higher maternal and perinatal morbidity and mortality, birth of low birth weight children and higher rates of puerperal infectious complications. The aim of the study was to seek, through an integrative review, to clarify the nutritional status and clinical complications of pregnant women with sickle cell anemia. For that, an exploratory study was carried out, through bibliographical research. With the selection and location of references taken from the PubMed/LILACS, Plos One and SciELO electronic library databases, also using the Virtual Health Library (VHL), in order to identify scientific articles published in the period between 2008 and 2020, using the following descriptors: sickle cell anemia and obstetric complications; sickle cell anemia and pregnant women; hemoglobin S and pregnant women and English versions. It was found that pregnant women with sickle cell anemia are more prone to complications, such as miscarriage, restricted intrauterine growth, increased intrauterine fetal mortality, low birth weight newborn, preterm labor, in addition to disability of macro and micronutrients during the gestational period, which can lead to maternal malnutrition and maternal and neonatal morbidity and mortality. In short, the susceptibility to maternal malnutrition, infections, hemolytic and vasoocclusive complications of pregnant women with sickle cell anemia proved to be an unfavorable prognosis, bringing with it complications for the mother and the newborn. Reinforcing the importance of nutritional monitoring as a prevention and guidance strategy regarding nutritional changes in pregnant women with the disease, as an alternative to minimizing adverse outcomes and ensuring improved maternal and fetal health.

Keywords: High-Risk Pregnancy. Obstetric complications. Pregnant. 


\section{INTRODUÇÃO}

A anemia falciforme é a doença genética mais comum no Brasil e envolve um grupo de hemoglobinopatias herdadas de elevada importância clínica e epidemiológica. Trata-se de uma enfermidade crônica geneticamente determinada com taxas de morbidade significativas e de alta prevalência no país (DINIZ et al., 2009).

As pessoas que são acometidas por essa doença estão sujeitas a uma série de complicações, como crises vaso-oclusivas e anemia hemolítica crônica que podem levar a maior susceptibilidade a infecções, acidente vascular cerebral, insuficiência renal, insuficiência cardíaca e hipertensão pulmonar, além de úlceras em membros inferiores de difícil cicatrização (SERJEANT et al., 2004; SMELTZER e BARE, 2005).

As complicações da DF na gravidez adquirem importância ainda maior, uma vez que o foco deixa de ser apenas a mulher, mas também para a relação mãe-feto. Somam-se a isso, as alterações fisiológicas da gestação que podem ser fatores desencadeantes de descompensação da DF (MONKEN et al., 2010).

Devido a essas complicações, a gravidez em mulheres com doença falciforme é considerada de alto risco. A gravidez de alto risco é aquela em que mãe e/ou o feto têm maior probabilidade de terem a saúde comprometida e a sua vida em risco em um percentual maior que as demais mulheres. A não realização do pré-natal, por si só, já pode ser considerado um fator de risco para a gestação e se acentua ainda mais em gestantes com anemia falciforme aumentando a importância de um atendimento multiprofissional, a fim de garantir que todos os aspectos da gravidez sejam abordados (BRASIL, 2001).

O diagnóstico de anemia falciforme não contraindica a gravidez, mas exige um acompanhamento diferenciado desde o pré-natal ao pós-parto, visto que as gestantes portadoras da doença tendem a ganhar menos peso do que as mulheres com hemoglobina normal, correlacionada com o peso ao nascer e comprometem o desenvolvimento fetal (ARMOND et al., 2003; THAME et al., 2014).

Durante o período gravídico em mulheres com anemia falciforme, é percebido um aumento da morbimortalidade materno fetal. Essas apresentam como principais complicações os abortos espontâneos, o crescimento intrauterino 
retardado, as infecções do trato urinário, a insuficiência cardíaca congestiva, os fenômenos tromboembólicos, a pré-eclâmpsia, a toxemia gravídica e as crises de dor óssea. Nesse contexto, espera-se que a identificação precoce dos eventos gestacionais das pacientes grávidas com anemia falciforme reduza as complicações perinatais (ZAGO et al., 2014; ARMOND et al., 2008).

Desse modo, diante da magnitude desta problemática, o presente estudo tem como objetivo esclarecer sobre o estado nutricional e as complicações clínicas de gestantes com anemia falciforme, com enfoque principal naquelas potencialmente graves e ameaçadoras de óbito ou que levam a óbito materno, assim, pretende-se que a identificação precoce dos eventos gestacionais das pacientes grávidas com anemia falciforme contribua para a redução de complicações perinatais.

\section{METODOLOGIA}

Realizou-se um estudo exploratório, através de pesquisa bibliográfica. A seleção e localização das referências foram retiradas das bases de dados PubMed/LILACS, Plos One, da biblioteca eletrônica SciELO e, ainda, da Biblioteca Virtual em Saúde (BVS), a qual integra as bases acima citadas, quando foram identificados artigos científicos relevantes sobre o tema publicados no período entre 2008 e 2020, utilizando os seguintes descritores: anemia falciforme e intercorrências obstétricas; anemia falciforme e gestante; hemoglobina $\mathrm{S}$ e gestante e suas versões em inglês.

Como critérios de inclusão foram atualizados artigos publicados nos idiomas português e inglês, disponíveis na íntegra, com acesso eletrônico livre e que correspondessem de forma fidedigna ao conteúdo da análise; já os de exclusão foram estudos repetidos, revisões bibliográficas e aquelas produções que não entraram em consonância com a proposta desta revisão e nem se enquadraram nos critérios de inclusão mencionados a partir da leitura dos títulos e resumos de cada um dos artigos científicos selecionados.

\section{RESULTADOS}

A busca inicial resultou em 86 publicações, sendo selecionados 10 estudos, os quais foram lidos na íntegra e adicionados para a construção desta revisão. 


\section{Foi elaborado um quadro contendo as principais características de cada} artigo: autor e ano de publicação, população estudada e objetivo (Quadro 1).

Quadro 1 - Descrição dos estudos incluídos ( $\mathrm{n}=10)$.

\begin{tabular}{|c|c|c|c|}
\hline & Autor, ano. & População estudada & Objetivo \\
\hline 2019 & Guzmán-Yara et al., & $\begin{array}{l}\text { Primigestante no } \\
\text { terceiro trimestre de gravidez } \\
\text { com diagnóstico de anemia } \\
\text { falciforme complicada pela } \\
\text { pré-eclâmpsia com } \\
\text { características de gravidade e } \\
\text { parto prematuro. }\end{array}$ & $\begin{array}{l}\text { Revisar } \\
\text { informações referentes à } \\
\text { incidência, morbimortalidade } \\
\text { materna e perinatal dessa } \\
\text { condição médica. }\end{array}$ \\
\hline & Desai G et al., 2017 & $\begin{array}{l}\text { Dados referentes a } \\
\text { quatro anos e meio, com um } \\
\text { total de internações maternas } \\
\text { de } 14640 \text {, dos quais } 10.519 \\
\text { internações foram partos. }\end{array}$ & $\begin{array}{l}\text { Comparar } \\
\text { desfechos da gravidez entre } \\
\text { DF, traço falciforme e } \\
\text { internações não-DF. Este } \\
\text { estudo também estimou o } \\
\text { risco de desfechos adversos } \\
\text { da gravidez para internações } \\
\text { com DF. }\end{array}$ \\
\hline 2016 & Baptista LC et al., & $\begin{array}{l}14 \text { mulheres com } \\
\text { SCD (HbSS, } \mathrm{n}=7 \text { e HbSC, } \mathrm{n} \\
=7) \text { e } 8 \text { mulheres com } \\
\text { gestações de controle não } \\
\text { complicadas }(\mathrm{n}=8) \text {. }\end{array}$ & \begin{tabular}{l}
\multicolumn{4}{c}{ Avaliar o perfil de } \\
expressão genética dos \\
mediadores de resposta \\
inflamatória nas placentas de \\
gestantes com anemia \\
falciforme (AF) \\
hemoglobinopatia SC (HbSC).
\end{tabular} \\
\hline 2016 & Paiva, Letícia Vieira, & $\begin{array}{l}\text { 26 } \\
\text { portadoras de } \begin{array}{r}\text { gestantes } \\
\text { anemia }\end{array} \\
\text { falciforme SS e } 23 \text { SC, a partir } \\
\text { do início do pré-natal } \\
\text { especializado até o puerpério. } \\
\text { Como grupo controle foram } \\
\text { utilizadas } 63 \text { gestantes sem } \\
\text { comorbidades. }\end{array}$ & \begin{tabular}{l}
\multicolumn{2}{c}{ Analisar 0 estado } \\
nutricional de gestantes \\
portadoras de anemia \\
falciforme, avaliando o ganho \\
de peso, o consumo dietético \\
materno e os resultados \\
adversos maternos \\
perinatais.
\end{tabular} \\
\hline & Meeks D et al., 2016 & $\begin{array}{l}\text { Foram analisados } \\
\text { centiles de peso ao nascer e } \\
\text { peso ao nascer para } 88 \\
\text { mulheres com SCD }(50 \\
\text { HBSS; } 38 \text { HbSC) e } 176 \\
\text { controles (HBAA). }\end{array}$ & $\begin{array}{l}\text { Analisar o peso médio } \\
\text { ao nascer e os percentis de } \\
\text { peso ao nascer de bebês } \\
\text { nascidos de mães com DF } \\
\text { versus mães com genótipo de } \\
\text { HbAA, para quantificar o risco } \\
\text { de ter um bebê menor. }\end{array}$ \\
\hline 2015 & Oteng & $\begin{array}{l}\text { Estudo nacional de } \\
\text { coorte usando o Uk Obstetric } \\
\text { Surveillance } \\
\text { (UKOSS) para identificar } \\
\text { gestantes com SCD. }\end{array}$ & $\begin{array}{l}\text { Descrever os achados } \\
\text { de um estudo nacional sobre } \\
\text { desfechos maternos e fetais } \\
\text { da gravidez em mulheres com } \\
\text { doença falciforme (DF). }\end{array}$ \\
\hline & Asma S et al., 2015 & $\begin{array}{l}37 \text { pacientes grávidas } \\
\text { com anemia falciforme. }\end{array}$ & $\begin{array}{l}\text { Avaliar } \\
\text { retrospectivamente } \\
\text { complicações da DF em } \\
\text { pacientes grávidas. }\end{array}$ \\
\hline 2012 & Al Kahtani MA et al., & $\begin{array}{lr} & 392 \text { casos de SCD na } \\
\text { gravidez e } 784 \text { controles com } \\
\text { fenótipo normal } & \text { de } \\
\text { hemoglobina, que } & \text { foram } \\
\text { selecionados } & \text { e }\end{array}$ & $\begin{array}{l}\text { Identificar } \\
\text { desfechos de morbidade e } \\
\text { gravidez associados à doença } \\
\text { falciforme (DF) em gestantes } \\
\text { sauditas. }\end{array}$ \\
\hline
\end{tabular}




\begin{tabular}{|c|c|c|}
\hline & $\begin{array}{l}\text { corresponderam para idade, } \\
\text { paridade e resultado do parto. }\end{array}$ & \\
\hline Thame $\mathrm{M}$ et al., & \begin{tabular}{l}
\multicolumn{1}{c}{128 partos $\quad$ em } \\
mulheres com doença ss que \\
foram combinados por idade \\
materna e data $r$ de \\
nascimento com 128 \\
controles com um fenótipo AA \\
normal.
\end{tabular} & $\begin{array}{l}\text { Avaliar o ganho de } \\
\text { peso da gravidez e } \\
\text { antropometria recém-nascido } \\
\text { em mães com doença } \\
\text { falciforme homozigo (SS) e } \\
\text { controles normais. }\end{array}$ \\
\hline 2010 Dormandy et al., & $\begin{array}{l}1708 \\
\text { elegíveis. }\end{array}$ & $\begin{array}{l}\text { Avaliar a eficácia da } \\
\text { oferta de triagem pré-natal } \\
\text { para doença falciforme e } \\
\text { talassemia na atenção } \\
\text { primária como forma de } \\
\text { facilitar a absorção precoce do } \\
\text { rastreamento. }\end{array}$ \\
\hline
\end{tabular}

Fonte: Autoria própria, 2021.

\section{DISCUSSÃO}

A literatura evidencia que gestantes portadoras de anemia falciforme possuem maior propensão a terem aborto espontâneo, crescimento intra-uterino restrito, aumento da mortalidade fetal intra-útero, recém-nascido de baixo peso, trabalho de parto pré-termo, somados à deficiência de macro e micronutrientes durante o período gestacional, podendo chegar à desnutrição materna e à morbimortalidade materna e neonatal.

Nesse viés, Dormandy e colaboradores (2010) puderam concluir que, ao oferecer uma triagem pré-natal para doença falciforme e talassemia na atenção primária, contribuiria para um tratamento precoce da paciente, resultando em uma gestação mais segura.

Já Asma e colaboradores (2015), ao estudarem 37 mulheres grávidas com anemia falciforme, reforçaram que há um aumento da mortalidade perinatal, particularmente durante o final da gravidez, havendo, também, um risco aumentado de complicações como pré-eclâmpsia, descolamento e dor aguda em mulheres grávidas e portadoras da DF. Além de uma alta taxa de cesarianas (22 pacientes, 91,6\%) quando comparado ao grupo controle (cinco pacientes, 62,5\%), apesar de não ter observado complicações cirúrgicas e médicas durante ou após a cesariana.

Na mesma linha de pesquisa, Guzmán-Yara e colaboradores (2019), reforçam que as complicações causadas pela anemia falciforme, no organismo do indivíduo, podem ter relação direta com a sua condição fisiopatológica e considera dois fatos fundamentais de destaque, sendo eles a vaso-oclusão intermitente e a 
anemia hemolítica crônica. E, fazendo a correlação dessa situação durante a gravidez, é percebido que essas alterações podem gerar ainda mais problemas devido ao fato da anemia fisiológica, o aumento da massa de eritrócitos, a requisição de maiores energias para atender às necessidades metabólicas do feto, a modulação imunológica, a estase vascular e a ativação do sistema de coagulação, além da ocorrência de infecções, incluindo pneumonia, sepse, bacteriúria assintomática e pielonefrite; o estado pró-trombótico - que aumenta o risco de tromboembolismo venoso - , trombose venosa profunda $\mathrm{e}$ tromboembolismo pulmonar, doenças hipertensas de gravidez, como a préeclâmpsia, parto prematuro e restrição de crescimento intrauterino, observações essas importantes para mostrar que a condição da DF pode ser, sim, um fator de agravamento para complicações durante o período gravídico.

Para complementar as informações acima, o estudo feito por Al Kahtani e colaboradores (2012) trouxe uma possível justificativa para o aumentado das taxas de natimortos e retardamento de crescimento intra-uterino (RCIU) relatados entre mulheres grávidas com DF, estando uma das explicações o fluxo sanguíneo placentário comprometido, secundário à vaso-oclusão materna da placenta que leva ao infarto placentário e função insuficiente, sendo esse cenário mais complicado devido ao efeito da anemia crônica na maternidade e da hipertensão induzida pela gravidez entre pacientes com DF.

Tal consideração se deu ao perceberem que o grupo de pacientes com DF teve uma prevalência significativamente maior de internações pré-parto $(60,0 \%$ contra $18,1 \%)$ e trabalho de parto prematuro $(13,0 \%$ contra $5,1 \%)$ em oposição ao grupo controle. Além disso, o grupo DF teve uma maior incidência de préeclâmpsia $(9,7 \%$ contra $3,2 \%)$ do que o grupo controle. Quanto às complicações da gravidez, foi observado, no presente estudo, quadros de anemia, infecções, toxemia, RCIU, trabalho de parto prematuro e internações hospitalares repetidas, todas as quais foram significativamente maiores entre o grupo DF do que o grupo de controle, reafirmando alguns dados encontrados no estudo de Guzmán-Yara e colaboradores (2019).

Já Oteng-Ntim e colaboradores (2015) trouxeram um panorama das condições clínicas gerais de gestantes portadoras de DF e mostraram que a maioria das gestações (88/109, 81\%) ocorreram em mulheres de 25 a 39 anos, 
com apenas 3,7\% das gestações em mulheres com mais de 40 anos, (54/109, $53,5 \%$ ) tinham um índice de massa corporal normal (IMC), mas seis delas (5,9\%) estavam abaixo do peso e $41(40,6 \%)$ com sobrepeso ou obesas. Em relação ao índice de gravidez, a maioria foi a primeira ou segunda gravidez em curso (42/109, $38,5 \%$ e 38/109, 34 9\% respectivamente), sendo que para seis mulheres $(5,5 \%)$ foi a quarta ou gravidez subsequente em curso. Dos tipos de DF, (51/109, 46 8\%) das mulheres eram HbSS, (44/109, 40 4\%) eram HbSC e (11/109, 10\%) foram outros genótipos.

Quanto aos parâmetros bioquímicos, a anemia era frequente com hemoglobina média $(\mathrm{Hb})$ nível de $85,7 \mathrm{~g} / \mathrm{l}$, tendo o grupo $\mathrm{HbSS}(65,5 \mathrm{~g} / \mathrm{l})$ a Hb média menor do que o grupo HbSC (104,5g/l). Foi percebido que mulheres com HbSS eram significativamente mais propensas do que mulheres com $\mathrm{HbSC}$ para receber uma transfusão durante a gravidez (43,1\% HbSS contra 6,8\% HbSC), tendo também, crises dolorosas, severas ou extremamente severas, crises dolorosas pós-parto mais comuns em mulheres com HbSS do que em HbSC.

Quanto ao parto, era mais provável de ocorrer a termo em mulheres com HbSC $(74,6 \%$ contra $35,4 \%$ em HbSS, $(P<0,001)$ e parto prematuro (<37 semanas) foi mais provável em mulheres com HbSS $(47,1 \%$ de mulheres com HbSS contra 20,5\% das mulheres com HbSC).

A cesariana foi realizada em 41 mulheres (38\%) e foi mais provável em mulheres com HbSS (53\%) do que em mulheres com $\mathrm{HbSC}(30 \%, \mathrm{P}=0,02)$ e o motivo mais comum para cesariana em mulheres com HbSS foi compromisso fetal (52\%, 13/25). Hemorragia pós-parto ocorreu em 18 mulheres (16,5\%) e era mais provável em mulheres com HbSC (25\%) do que HbSS (7,8\%).

Já Baptista e colaboradores (2016) observaram que a expressão gênica pode influenciar em algumas particularidades de gestantes com DF, tais como: as mulheres com o HbSS genótipo apresentaram idade gestacional ao parto e peso ao nascer significativamente menores $(35,0 \pm 3,9$ semanas, $P=0,02$ e 226,5 \pm $872,8 \mathrm{~g}, \mathrm{P}=0,04)$ do que as mulheres do grupo controle $(38,9 \pm 1,7$ semanas $\mathrm{e}$ $2946 \pm 585,4$ g), apesar de não apresentarem diferenças estatisticamente significativas em termos de altura ao nascer e peso da placenta.

Foram percebidas, também, diferenças quanto às complicações relacionadas com a falcização durante a gravidez, sendo mais frequentes no 
grupo HbSS do que no grupo HbSC: crises vaso-oclusivas (57,1 contra 42,9\%), RCIU (28,6 contra $0 \%$, mortalidade perinatal (14,2 contra $0 \%$ ), admissão hospitalar durante a gravidez (71,4 vs. 28,6\%), e admissão à unidade de terapia intensiva durante a gravidez (14,2 contra $0 \%)$.

Desai e colaboradores (2017), trouxeram uma relação da prevalência de gestantes com DF, com traços e sem DF e seus desfechos, e obtiveram os seguintes resultados: de sua população total do estudo, 1,2\% (131 de 10.519) das admissões de parto por células falciformes, outros 15,6\% (1645 de 10519) das admissões de parto têm traço falciforme. Quanto aos desfechos perinatais, o percentual de natimortos foi de 9,9\% entre as células falciformes em comparação com $4,2 \%$ entre as admissões de parto não falciforme; $70,2 \%$ entre os partos de células falciformes tinham baixo peso ao nascer em comparação com 43,8\% dos pacientes não falciformes. Da mesma forma, quase metade dos partos de células falciformes precisava da transfusão de sangue.

Os $45 \%$ das admissões por parto falciforme foram nascimentos prematuros, em comparação com 17,3\% em entregas sem DF. A razão de chances de anemia grave, natimorto, transfusão de sangue, cesariana e baixo nascimento o peso foi significativamente maior para as admissões por células falciformes em comparação com as admissões não falciformes.

Paiva (2016) trouxe, em seu estudo, dados referentes à relação do estado nutricional de gestantes portadoras de anemia falciforme do tipo SS quando comparadas com as do tipo SC e com o grupo controle, onde foi percebido que o estado nutricional das gestantes portadoras de hemoglobinopatia SS caracterizou-se pela desnutrição materna, tendo um ganho de peso materno na gestação menor quando comparadas aos grupos SC e controle, além disso, foi percebido que em relação ao consumo dietético de macronutrientes no $2^{\circ}$ trimestre e no $3^{\circ}$ trimestre, as portadoras de hemoglobinopatias SS e SC apresentaram menor consumo de proteínas e verificou-se menor consumo de calorias no grupo SC, respectivamente. As gestantes dos grupos SS apresentaram complicações maternas mais frequentes, e as portadoras de hemoglobinopatias SS e SC apresentaram menor idade gestacional no parto, e o grupo SS mostrou, com mais frequência, o diagnóstico de sofrimento fetal, o parto 
pela cesárea, índices de Apgar inferiores a 7 no $1^{\circ}$ minuto e maior perda perinatal, em relação ao grupo controle representando os resultados perinatais.

Thame e colaboradores (2011) observaram que mães com doença SS tinham peso e índice de massa corporal menores na primeira consulta pré-natal ( $\mathrm{P}<0,001)$. O ganho de peso total foi de 6,9 $\mathrm{kg}$ para mulheres SS e 10,4 kg para controles AA $(P<0,001)$ e ganho de peso semanal de 0,263 kg $(95 \% \mathrm{Cl} 0,224$, $0,301)$ e $0,396 \mathrm{~kg}(95 \% \mathrm{Cl} 0,364,0,427)$, respectivamente. Uma relação significativa ocorreu entre o peso ao nascer e o ganho de peso materno em 25-30 semanas de gestação em controles $A A$, mas essa relação parece atrasada na doença de SS. Diferentes padrões de ganho de peso materno em mães SS e controles normais podem ter significância para o menor peso ao nascer em mães SS.

Por fim, Meeks e colaboradores (2016) trouxeram diferenças estatisticamente significativas na média de peso ao nascer e percentis médios do peso ao nascer. Eles perceberam que a idade média foi de 29,6 anos em ambos os grupos DF (28,5 anos em HbSS; 31,0 anos em HbSC grupos) e grupo controle. O IMC médio no grupo DF foi de $25,0 \mathrm{~kg} / \mathrm{m}^{2}\left(22,5 \mathrm{~kg} / \mathrm{m}^{2}\right.$ em HbSS e $28,3 \mathrm{~kg} / \mathrm{m}^{2}$ em grupos HbSC) e 27,3 kg/m² no grupo de controle. Não houve diferenças estatisticamente significativas nas taxas de (pequeno para idade gestacional) PIG ou BPN (baixo peso ao nascer) entre os grupos DF e HbAA. As principais diferenças entre o DF e o grupo de controle foram o peso médio ao nascer e percentil médio do peso ao nascer. O peso médio geral ao nascer para as gestações com DF foi de $2.918 \mathrm{~g}$ em comparação com um peso médio ao nascer de $3.176 \mathrm{~g}$ para os controles. O peso médio ao nascer do recém-nascidos de mães com DF foi significativamente menor em $258 \mathrm{~g}$ abaixo das contrapartes HbAA.

De acordo com os resultados, o percentil médio do peso ao nascer para o DF partos (percentil 32,8) foi significativamente menor do que os controles (percentil 42,2) com uma diferença de 9,4 percentis. O peso médio ao nascer, nesse caso, foi de $3.025 \mathrm{~g}$ (intervalo interquartil $=2.740-3.270 \mathrm{~g}$ ) para o grupo DF e $3.200 \mathrm{~g}$ (intervalo interquartil $=2.890-3.545 \mathrm{~g}$ ) para os controles.

Eles concluíram que taxa de prematuridade (definida como nascimento antes da $37^{\text {a }}$ semana de gestação) foi de $10,2 \%(n=9)$ para o grupo SCD (IC 95\% $=5,3 \%-18,7 \%)$ e $9,1 \%(n=16)$ para o grupo de controle (IC 95\% = 5,6\% -14,4\%). 


\section{CONSIDERAÇÕES FINAIS}

Diante do exposto, considera-se, de forma esclarecida, que a gravidez em mulheres com DF apresenta risco aumentado de mortalidade materna, préeclâmpsia, parto prematuro e natimorto.

A suscetibilidade à desnutrição materna, infecções e complicações hemolíticas e vaso-oclusivas de gestantes com anemia falciforme mostrou-se como um prognóstico desfavorável, trazendo consigo complicações para a mãe e o neonato.

O cuidado pré-natal, acompanhamento clínico e laboratorial, além de transfusões, tiveram um impacto significativo na redução da mortalidade neonatal na DF. Porém, apesar dos avanços, a gravidez em mulheres com DF ainda está associada com complicações clínicas e obstétricas.

Ainda há muito a se discutir acerca de tal assunto, porém, tais resultados reforçam a importância do acompanhamento nutricional como estratégia de prevenção e orientação relativas às alterações nutricionais das gestantes portadoras da doença, como alternativa para a minimização dos resultados adversos e garantir melhoria da saúde materna e fetal. 


\section{REFERÊNCIAS}

AL KAHTANI, Maryam A. et al. Morbidity and pregnancy outcomes associated with sickle cell anemia among Saudi women. International Journal of Gynecology \& Obstetrics, v. 119, n. 3, p. 224-226, 2012.

ARMOND, Sandra Cristina. Complicações intercorrentes no período gestacional e resultado perinatal de pacientes portadoras de hemoglobinopatia SS e SC. 2003.

Asma S, Kozanoglu I, Tarım E, Sarıturk C, Gereklioglu C, Akdeniz A, Kasar M, Turgut $\mathrm{NH}$, Yeral $\mathrm{M}$, Kandemir $\mathrm{F}$, Boga $\mathrm{C}$, Ozdogu $\mathrm{H}$. A troca profilática de glóbulos vermelhos pode ser benéfica no tratamento da doença falciforme na gravidez. Transfusão, v. 55, n. 1, pág. 36-44, 2015.

BAPTISTA, Letícia C. et al. Expressão anormal de genes inflamatórios em placentas de mulheres com anemia falciforme e hemoglobina $C$ falciforme. Annals of hematology , v. 95, n. 11, pág. 1859-1867, 2016.

BRASIL. Ministério da Saúde. Secretaria executiva. Gestante de alto risco: sistemas estaduais de referência hospitalar à gestante de alto risco. Ministério da Saúde, Secretaria executiva. Brasília: Ministério da Saúde, 2001. P. 32.

DESAI, Gayatri et al. Sickle cell disease and pregnancy outcomes: a study of the community-based hospital in a tribal block of Gujarat, India. Journal of Health, Population and Nutrition, v. 36, n. 1, p. 1-7, 2017.

DINIZ, Debora et al. Prevalência do traço e da anemia falciforme em recémnascidos do Distrito Federal, Brasil, 2004 a 2006. Cadernos de Saúde Pública, v. 25, p. 188-194, 2009.

DORMANDY, Elizabeth et al. Effectiveness of earlier antenatal screening for sickle cell disease and thalassaemia in primary care: cluster randomised trial. Bmj, v. 341, 2010.

GUZMÁN-YARA, Yuly Natalia et al. Anemia Falciforme e Gravidez. Relato de caso. Revista Health Forest , v. 9, n. 2 P. 65-72, 2019.

Meeks D, Robinson SE, Macleod D, Oteng-Ntim E. Peso ao nascer em gestações com doença falciforme: um estudo de coorte. PloS One, v. 11, n. 10, pág. e0165238, 2016.

MONKEN, Frederico Vilanova et al. Situações de urgência na gestante com doença falciforme. Rev méd Minas Gerais, v. 20, n. 2, p. 73-7, 2010.

OTENG-NTIM, Eugene et al. Pregnancy outcome in patients with sickle cell disease in the UK-a national cohort study comparing sickle cell anaemia $(\mathbf{H}$ b SS) with H b SC disease. British Journal of Haematology, v. 169, n. 1, p. 129137, 2015. 
PAIVA, Letícia Vieira de. Nutrição da gestante portadora de anemia falciforme, complicações maternas e resultados perinatais. 2016. Tese de Doutorado. Universidade de São Paulo.

SERJEANT, Graham R. et al. Resultado da gravidez na doença falciforme homozigótica. Obstetrícia e Ginecologia , v. 103, n. 6, pág. 1278-1285, 2004.

SMELTZER, Suzanne C.; BARE, Brenda G. Brunner \& Suddarth, Tratado de enfermagem médico-cirúrgica. In: Brunner \& Suddarth, Tratado de enfermagem médico-cirúrgica. 2005. p. 1133-1133.

Thame M, Lewis J, Hambleton I, Trotman H, Serjeant G. Padrão de ganho de peso na gravidez na doença falciforme homozigótica e efeito no tamanho do nascimento. Revista Médica das Índias Ocidentais , v. 60, n. 1, 2011.

ZAGO, Marco Antonio; PINTO, Ana Cristina Silva. Fisiopatologia das doenças falciformes: da mutação genética à insuficiência de múltiplos órgãos. Revista Brasileira de Hematologia e Hemoterapia, v. 29, p. 207-214, 2007. 